\title{
EL ACCESO A LA JUSTICIA Y LA PROTECCION DE LA SALUD
}

\author{
Sandra Regina Martini \\ Centro Universitário Ritter dos Reis. Porto Alegre/RS, Brasil.
}

Claudia Zalazar

Instituto de Investigación en Ciencias Jurídicas de la Universidad Blas Pascal. Córdoba, Argentina.

\section{Gabrielle Jacobi Kolling}

Autora correspondente. Complexo de Ensino Renato Saraiva (CERS); Strong Business School (STRONG). http://lattes.cnpq. br/4913726405596681. https://orcid.org/0000-0003-2225-555X. koll.gabrielle@gmail.com

\section{RESUMEN}

El derecho a la salud en la sociedad actual es desafiado constantemente en cuanto a la efectividad. Las Constituciones contemporáneas, entre las cuales la argentina y la brasileña, consolidan la salud como derecho. El reto de estos sistemas jurídicos reside en la materialización de la salud. Ante el contexto de la denominada "crisis del Estado", nace el fenómeno de la judicialización de la salud. Así, el objetivo del artículo es analizar el derecho a la salud en el contexto de la judicialización de la salud en Argentina y Brasil. En lo que concierne a la metodología, se destaca que el artículo está enraizado en la revisión de literatura del tema. Por último, se percibe que el punto común entre la judicialización entre los dos países es accesibilidad de los servicios de salud y la necesaria expansión del poder judicial.

Palabras-clave: Acceso a la justicia; salud; jurisdicción; legalización; Estado; accesibilidad.

\section{ACESSO À JUSTIÇA E PROTEÇÃO DA SAÚDE}

RESUMO

O direito à saúde na sociedade atual é desafiado constantemente no tocante à efetivação. As Constituições contemporâneas, entre as quais a argentina e a brasileira, consolidam a saúde como direito. O desafio desses sistemas jurídicos reside na concretização da saúde. Diante do contexto da denominada "crise do Estado", nasce o fenômeno da judicialização da saúde. Assim, o objetivo do artigo é analisar o direito à saúde no contexto da judicialização da saúde na Argentina e no Brasil. No que respeita à metodologia, destaca-se que o artigo está baseado na revisão de literatura do tema. Por fim, percebe-se que o ponto comum entre a judicialização entre os dois países é a acessibilidade dos serviços de saúde e a necessária expansão do poder judicial.

Palavras-chave: Acesso à justiça; saúde; jurisdição; judicialização; Estado; acessibilidade.

Recebido em: $26 / 7 / 2019$

Aceito em: $31 / 5 / 2021$ 


\section{Humanos e \\ Democracia}

\section{INTRODUCCIÓN}

A lo largo de la historia, los ciudadanos han buscado encontrar en un tercero el apoyo para lograr la resolución de sus conflictos, es decir, las pretensiones resistidas por diferencias sobre alguna cuestión de hecho o la aplicación del derecho.

Con el nacimiento del Estado y el fortalecimiento de las estructuras de poder, la Justicia se consolidó como el espacio adecuado para aplicar una solución idónea en la persona de un tercero imparcial que mira a las partes y a lo que ellas prueban y, aplicando el derecho, trata de recomponer el orden jurídico alterado.

Con el paso de los años y el crecimiento de las estructuras de poder, el acceso de los ciudadanos a una solución estatal ha sido complejo, puesto que se han encontrado con barreras no sólo de esas estructuras, sino también de sus condiciones. Así, las personas se han visto discriminadas o alejadas de la justicia por no tener dinero, por tener una nacionalidad determinada, un color de piel o un nivel de estudios. En este escenario, "Ia igualdad real se convierte, entonces, en el presupuesto indeficiente del equilibrio social" (BERIZONCE, 1987, p. 8), y la búsqueda de la restauración de ese equilibrio es tarea primordial de la justicia.

En este íter, la reconstrucción de los lazos afectados ha sido y es un problema en los Estados que forman parte del Sistema Interamericano, porque hubo que cambiar la forma de pensar de gobernantes, jueces, legisladores y ciudadanos y dar el paso necesario al reconocimiento a través de políticas gubernamentales, leyes y sentencias al derecho de acceso a la justicia, ya que "la defensa judicial de los derechos asume una significación superlativa, porque su consagración exige el libre e irrestricto acceso a la jurisdicción" (BERIZONCE, 1987, p. 9).

Somos contestes en comprender que el Estado no puede quedar aislado de buscar una solución al problema que aqueja a tantos justiciables y que el reconocimiento de este derecho no debe ser sólo una promesa, sino que debe ir de la mano de una serie de cambios que permitan comprender que el acceso a la justicia es "(...) un derecho humano fundamental en un sistema democrático que tenga por objeto garantizar los derechos de todos por igual" (BIRGIN; KOHEN, 2006, p. 1).

Entendemos al acceso a la justicia como "un acceso de todos a los beneficios de la Justicia y del asesoramiento legal y judicial, en forma adecuada a la importancia de cada tema o asunto, sin costos o con costos accesibles, por parte de todas las personas físicas y jurídicas, sin discriminación alguna por sexo, raza, religión o nacionalidad" (SARTORI, 2010, p. 261). Es un derecho con múltiples facetas y en conexión con un cúmulo de situaciones, lo que demuestra la complejidad de su aprehensión y la amplitud de su espectro.

En la República Argentina se ha dado jerarquía constitucional a una serie de Tratados Internacionales de Derechos Humanos en la Reforma Constitucional del año 1994, estando 
éstos a la misma altura que la Máxima Ley, en virtud del Art. 75 Inc. 22, " "de tal forma que los tratados de derechos humanos que poseen jerarquía constitucional, acompañan a la Constitución y son los establecidos expresamente por el art. 75, inc. 22" (BUSTAMANTE CANO, 2001, p. 2).

Estos virajes han llevado a un cambio de paradigmas, porque los Jueces no sólo deben juzgar a la luz del control de constitucionalidad, sino que deben ampliar el control hasta llegar a que los actos se encuentren de acuerdo con estos Tratados, en lo que se ha dado en llamar "Control de Convencionalidad" y particularmente fallar conforme a los principios de los tratados de derechos humanos. Respecto de aquel control primigenio, se ha dicho que "Ia mutación de sus principios clásicos hacia pautas neoconstitucionales, no sin zigzagueos, ha experimentado una verdadera transformación del instituto en aras de lograr una mayor tutela constitucional de los derechos de las personas" (CAO, 2010, p. 1).

\footnotetext{
Cfr. Art. 75 Inc. 22: [Corresponde al Congreso: Aprobar o desechar tratados concluidos con las demás naciones y con las organizaciones internacionales y los concordatos con la Santa Sede. Los tratados y concordatos tienen jerarquía superior a las leyes. La Declaración Americana de los Derechos y Deberes del Hombre; la Declaración Universal de Derechos Humanos; la Convención Americana sobre Derechos Humanos; el Pacto Internacional de Derechos Económicos, Sociales y Culturales; el Pacto Internacional de Derechos Civiles y Políticos y su Protocolo Facultativo; la Convención sobre la Prevención y la Sanción del Delito de Genocidio; la Convención Internacional sobre la Eliminación de todas las Formas de Discriminación Racial; la Convención sobre la eliminación de todas las Formas de Discriminación contra la Mujer; la Convención contra la Tortura y otros Tratos o Penas Crueles, Inhumanos o Degradantes; la Convención sobre los Derechos del Niño; en las condiciones de su vigencia, tienen jerarquía constitucional, no derogan artículo alguno de la primera parte de esta Constitución y deben entenderse complementarios de los derechos y garantías por ella reconocidos. Sólo podrán ser denunciados, en su caso, por el Poder Ejecutivo nacional, previa aprobación de las dos terceras partes de la totalidad de los miembros de cada Cámara. Los demás tratados y convenciones sobre derechos humanos, luego de ser aprobados por el Congreso, requerirán del voto de las dos terceras partes de la totalidad de los miembros de cada Cámara para gozar de la jerarquía constitucional, Constitución de la Nación Argentina. Corresponde al Congreso: Aprobar o desechar tratados concluidos con las demás naciones y con las organizaciones internacionales y los concordatos con la Santa Sede. Los tratados y concordatos tienen jerarquía superior a las leyes.

La Declaración Americana de los Derechos y Deberes del Hombre; la Declaración Universal de Derechos Humanos; la Convención Americana sobre Derechos Humanos; el Pacto Internacional de Derechos Económicos, Sociales y Culturales; el Pacto Internacional de Derechos Civiles y Políticos y su Protocolo Facultativo; la Convención sobre la Prevención y la Sanción del Delito de Genocidio; la Convención Internacional sobre la Eliminación de todas las Formas de Discriminación Racial; la Convención sobre la Eliminación de todas las Formas de Discriminación contra la Mujer; la Convención contra la Tortura y otros Tratos o Penas Crueles, Inhumanos o Degradantes; la Convención sobre los Derechos del Niño; en las condiciones de su vigencia, tienen jerarquía constitucional, no derogan artículo alguno de la primera parte de esta Constitución y deben entenderse complementarios de los derechos y garantías por ella reconocidos. Sólo podrán ser denunciados, en su caso, por el Poder Ejecutivo nacional, previa aprobación de las dos terceras partes de la totalidad de los miembros de
} cada Cámara.

Los demás tratados y convenciones sobre derechos humanos, luego de ser aprobados por el Congreso, requerirán del voto de las dos terceras partes de la totalidad de los miembros de cada Cámara para gozar de la jerarquía constitucional.

Aprobar o desechar tratados concluidos con las demás naciones y con las organizaciones internacionales y los concordatos con la Santa Sede. Los tratados y concordatos tienen jerarquía superior a las leyes.

La Declaración Americana de los Derechos y Deberes del Hombre; la Declaración Universal de Derechos Humanos; la Convención Americana sobre Derechos Humanos; el Pacto Internacional de Derechos Económicos, Sociales y Culturales; el Pacto Internacional de Derechos Civiles y Políticos y su Protocolo Facultativo; la Convención sobre la Prevención y la Sanción del Delito de Genocidio; la Convención Internacional sobre la Eliminación de todas las Formas de Discriminación Racial; la Convención sobre la Eliminación de todas las Formas de Discriminación contra la Mujer; la Convención contra la Tortura y otros Tratos o Penas Crueles, Inhumanos o Degradantes; la Convención sobre los Derechos del Niño; en las condiciones de su vigencia, tienen jerarquía constitucional, no derogan artículo alguno de la primera parte de esta Constitución y deben entenderse complementarios de los derechos y garantías por ella reconocidos. Sólo podrán ser denunciados, en su caso, por el Poder Ejecutivo nacional, previa aprobación de las dos terceras partes de la totalidad de los miembros de cada Cámara.

Los demás tratados y convenciones sobre derechos humanos, luego de ser aprobados por el Congreso, requerirán del voto de las dos terceras partes de la totalidad de los miembros de cada Cámara para gozar de la jerarquía constitucional. 


\section{Democracia}

Humanos e

En este orden de ideas, cabe destacar que el Estado Argentino -como el Brasilero - forman parte del Sistema Interamericano y está sujeto como cualquier otro Estado al cumplimiento de los compromisos asumidos y de las decisiones que emanan de la Corte Interamericana y de la Comisión Interamericana de Derechos Humanos, como así también que debe cumplir con las normas de este esquema regional, que integran el bloque de constitucionalidad nacional.

Sobre este marco, debemos preguntarnos acerca de cuál es la real vigencia que tiene hoy en ambos países el reconocimiento del acceso a la justicia como derecho, a la luz de los estándares del sistema regional. Sabemos claramente que "los organismos del Sistema Interamericano se han pronunciado reiteradamente en torno al acceso a la justicia, considerándolo uno de los fundamentales no sólo de la Convención Americana, sino del propio Estado de Derecho en una sociedad democrática" (PÉREZ CURCI, 2014, p. 1). Cabe ver, entonces, cómo se ha proyectado esto en la esfera de actuación de la justicia de cada país.

Así las cosas, pensamos que, si bien existen Resoluciones de la Asamblea General, Informes y Resoluciones del Comité Jurídico Interamericano, Mandatos del Departamento de Derecho Internacional y otros documentos de gran valor, nuestros sistemas jurídicos no han asumido en su totalidad el acervo regional y, en muchos casos, han acudido a la norma interna desconociendo la amplitud del sistema.

Es necesario, entonces, resignificar a este derecho, el que "impone la exigencia de tornar efectivas las garantías constitucionales de igualdad y debido proceso que implican la tutela de los derechos para todos los habitantes, sin trabas y a resguardo de restricciones, obstáculos y menoscabos"(SARTORI, 2010, p. 257).

Así, bajo la óptica del Sistema Interamericano de Derechos Humanos y sobre la especial relevancia que tiene el acceso a la justicia, entendemos que en las sentencias no ha habido un desarrollo amplio del esquema argumentativo basado en éste derecho y en la interrelación que tiene con una multiplicidad de otros derechos, circunstancias y momentos jurídicos sobre la base de las riquezas que éste Sistema puede aportar.

\section{LA PROTECCIÓN DE LA SALUD EN ARGENTINA}

El derecho a la salud, a diferencia de otros derechos sociales, no ha tenido un adecuado tratamiento constitucional en la República Argentina. La primera referencia se encuentra en el texto de la reforma constitucional de 1957, en el art. 14 bis, que lo menciona de manera indirecta al consignar que el Estado debe otorgar: "los beneficios de la seguridad social, que tendrá carácter de integral e irrenunciable", y el establecimiento de un "seguro social obligatorio". Es decir, no existía una garantía expresa a la salud como derecho, sino que la disposición se relaciona con la cobertura de contingencias sociales vinculadas a la inserción laboral formal y asalariada.

Es recién a partir de la reforma constitucional de 1994 cuando se reconoce la tutela y la protección de la salud por diversas vías. Una primera referencia explícita se encuentra en el art. 42 que reconoce el derecho de los consumidores y usuarios de bienes y servicios a la: "protección de la salud y seguridad" en la relación de consumo. La segunda vía protectora, y 


\section{Democracia}

Humanos e

de mayor alcance, se logró al otorgar jerarquía constitucional a once declaraciones y tratados internacionales de derechos humanos en el art. 75 inc. 22 de la CN.

Específicamente, como consecuencia del art. 12 del Pacto Internacional de Derechos Económicos, Sociales y Culturales (PIDESC), que define a la salud como: "el derecho de toda persona al disfrute del más alto nivel posible de salud física y mental", el Estado queda jurídicamente obligado a garantizar el contenido mínimo de los derechos económicos, sociales y culturales, y no puede escudarse en la falta de recursos disponibles para justificar su incumplimiento. Por su parte, el art. 25 de la Declaración de los Derechos Humanos dispone que toda persona tiene derecho a un nivel de vida adecuado que le asegure, así como a su familia, la salud y bienestar, y en especial la asistencia médica y los servicios sociales necesarios. Asimismo, el art. XI de la Declaración de Derechos y Deberes del Hombre establece que toda persona tiene derecho a que su salud sea preservada por medidas sanitarias y sociales relativas a la alimentación, el vestido, la vivencia, la asistencia médica correspondiente al nivel que permitan los recursos públicos y los de la comunidad; entre otros.

El derecho a la salud está íntimamente vinculado al derecho a la vida y ése ha sido reputado por la Corte Suprema de justicia de la Nación como el primer derecho de la persona humana que resulta reconocido y garantizado por la Constitución Nacional (Fallos 323:3229; 330:4647); haciendo hincapié en el principio "pro homine". Este principio en el ámbito de los derechos humanos implica generar una presunción asegurando a la persona humana la prevalencia por sobre cualquier otro principio. Así se ha dicho que: "El principio pro homine es un criterio hermenéutico que informa todo el derecho de los derechos humanos, en virtud del cual se debe acudir a la norma más amplia, o a la interpretación más extensiva, cuando se trata de reconocer derechos protegidos e, inversamente, a la norma o a la interpretación más restringida cuando se trata de establecer restricciones permanentes al ejercicio de los derechos o a sus suspensión extraordinaria" (PINTO, 1997, p.163).

Ergo, no hay duda que dentro del amplio espectro de los derechos humanos, se debe velar y proteger el derecho a la salud, ya que ella hace a la vida misma del ser humano. Al respecto y con una visión desde la bioética se señaló que: “...la salud no solo debe ser garantizado porque es un derecho que está positivizado (...) sino porque es antes que ello, un objetivo de derecho natural confiado a la custodia del Estado. Huelga decir que es tal: derecho natural; por ser sin más él mismo, una clara extensión prolongación, derivación o corolario -del mismo derecho a la vida. El derecho a la salud en definitiva no puede ser pensado disociadamente del derecho a la vida; la ausencia de salud es primero enfermedad y finalmente no vida; obviamente que también entre nacer y morir, el mencionado derecho a la salud se interrelaciona con una totalidad de otros derechos, que hacen seriamente pensar que sin salud aunque ontológicamente es antes siempre sin vida -resulta inaccesible gozar de otros derechos..." (ANDRUET, 2004, p. 107).

En esta línea argumental es clara la consigna que el Estado Federal es el primer garante del sistema de salud, independientemente de la existencia de obligaciones en cabeza de otros sujetos o los llamados servicios complementarios. En Argentina debemos distinguir, por un lado, el servicio de salud pública, prestado por el Estado; y por otro el sistema de las obras sociales (con clientes cautivos que son los empleados de determinado sector-salvo los adherentes voluntarios) junto con los organismos privados como son las empresas de medicina 


\section{Democracia}

Humanos e

prepaga en las cuales sus afiliados se adhieren al sistema, constituyendo sin duda, un típico caso de contrato de consumo.

Lorenzetti señaló que el legislador puede establecer un sistema público o privado de salud y que esta es una elección legítima, pero en el último caso hay un piso mínimo que debe garantizar pues pueden existir desigualdades en la asignación de los servicios médicos como derecho fundamental (LORENZETTI, p. 18-19); a tal fin el Estado creó el Sistema Nacional Integrado de Salud "a efectos de procurar el pleno goce del derecho a la salud para todos los habitantes del pais" (art. 1 de la ley 23.661).

En definitiva, el derecho a la salud impone obligaciones positivas y negativas al Estado, no sólo sobre otros entes estatales (políticas de salud pública), sino también sobre organismos privados que son prestadores de salud, como las prestadoras de medicina prepaga, ya que insistimos aquél es el primer garante del sistema de salud.

Sin embargo, con la sanción del Código Civil y Comercial de la Nación se creó un denominado "núcleo duro de salud", conforme al cual las directivas establecidas por esta última normativa de alcance nacional debe ser respetada por todos sus habitantes; sin perjuicio en su caso de la aplicación de las legislaciones especiales (en caso de silencio de las normas en el código fondal). A ello debemos sumarle que dicha normativa sustancial legisla no sólo sobre las cuestiones patrimoniales sino también las extrapatrimoniales, haciendo especial hincapié en los derechos de las personas desde su nacimiento hasta su muerte, regulando así el cuidado del cuerpo, de la salud, etc.

La Corte Interamericana de Derechos Humanos $(\mathrm{CIDH})$ se pronunció por primera ocasión respecto el derecho a la salud de manera autónoma, como parte integrante de los Desca, como un derecho justiciable a la luz de la Convención Americana. Concretamente, la Corte resolvió que "...la salud es un derecho humano fundamental e indispensable para el ejercicio adecuado de los demás derechos humanos. Todo ser humano tiene derecho al disfrute del más alto nivel posible de salud que le permita vivir dignamente167, entendida la salud168, no sólo como la ausencia de afecciones o enfermedades, sino también a un estado completo de bienestar físico, mental y social, derivado de un estilo de vida que permita alcanzar a las personas un balance integral. El Tribunal ha precisado que la obligación general se traduce en el deber estatal de asegurar el acceso de las personas a servicios esenciales de salud, garantizando una prestación médica de calidad y eficaz, así como de impulsar el mejoramiento de las condiciones de salud de la población". ${ }^{2}$

En definitiva, es dable señalar que el Estado está facultado a imponer obligaciones a sujetos privados, como a las obras sociales y a las empresas de medicina prepaga, en materia de salud, y que los prestadores privados tienen obligaciones especiales de cuidado hacia sus clientes y usuarios, que exceden el carácter de mero trato comercial. ${ }^{3} \mathrm{~A}$ ello debemos agregar que tanto en la faz privada, como en la pública, tiene una fuerte impronta la aplicación de las normas y principios del derecho del consumidor; lo que nos ha llevado a contemplar el presente tema: el paciente como consumidor.

\footnotetext{
Corte Interamericana de Derechos Humanos, "Poblete Vilches y otros vs. Chile", Sentencia de 8 marzo de 2018 (Fondo, Reparaciones y Costas). Parágrafo 118. Disponible en: http://www.corteidh.or.cr/docs/casos/articulos/seriec_349_esp.pdf.

3 Corte Suprema de Justicia de la Nación, "Unión de Usuarios y Consumidores c/ Compañía Euromédica de Salud S.A." - sentencia del 08/04/2008 - LA LEY 13/05/2008.
} 


\section{Democracia}

Humanos e

Así se ha dicho que: "...corresponde al Estado Nacional velar por el fiel cumplimiento de los tratamientos requeridos, habida cuenta de la función rectora que le atribuye la legislación nacional y de las facultades que debe ejercer para coordinar e integrar sus acciones con las autoridades provinciales y diferentes organismos que conforman el sistema sanitario del país en miras a lograr la plena realización del derecho a la salud", "...lo dispuesto en los tratados internacionales que tienen jerarquía constitucional (art. 75, inc. 22 de la Ley Suprema) reafirma el derecho a la preservación de la salud - comprendido dentro del derecho a la vida - y destaca la obligación impostergable de la autoridad pública de garantizar ese derecho con acciones positivas, sin perjuicio de las obligaciones que deben asumir en su cumplimiento las jurisdicciones locales, las obras sociales o las entidades de la llamada medicina prepaga ...", "... que resulta evidente la función rectora que ejerce el Estado Nacional en el campo de la salud y la labor que compete al Ministerio de Salud y Acción Social, como autoridad de aplicación, para garantizar la regularidad de los tratamientos sanitarios coordinando sus acciones con las obras sociales y los estados provinciales, sin mengua de la organización federal y descentralizada que corresponda para llevar a cabo tales servicios...". ${ }^{4}$

Ahora bien, muchas veces la realidad nos demuestra que tanto el Estado como las obras sociales y las empresas de medicina prepaga en los últimos tiempos, vienen consolidando la aplicación de la teoría del incumplimiento eficiente (menor costo es no cumplir, que cumplir) desarrollada por la escuela de análisis económico de Chicago. En este sentido Ghersi señala que: "Lamentablemente de aquel viejo principio liberal de los "contratos están para cumplirse", el neoliberalismo estatal y empresarial lo han transformado en este siglo 21 en el principio: los contratos no se cumplen para lograr mejor poder de negociación en el cumplimiento de prestaciones de salud con posterioridad al incumplimiento o la reparación del daño" (GHERSI, 2012).

Estas conductas sin duda alguna han provocado una mayor judicialización de la salud; lo que debe ser erradicado justamente atento a la actual tendencia a la desjudicialización de la salud, bregando por el cumplimiento de los deberes a cargo de los prestadores sin tener que llegar a la justicia para obtenerlo.

En definitiva, a la luz de los derechos humanos debemos pregonar que el Estado, desde todos sus poderes, vele por el cumplimiento de los objetivos que son primordiales para los ciudadanos -como la salud de la población -, ya que de no ser así, las leyes sancionadas en la materia no dejarían de ser sino enfáticas enumeraciones programáticas vacías de operatividad y en definitiva lejanas a garantizar la protección que la salud merece.

Al respecto, la CIDH destacó que: "ya en el caso Suárez Peralta que el Estado debe prever mecanismos de supervisión y fiscalización estatal de las instituciones de salud, tanto públicas como privadas. Al respecto, la Corte ha señalado que cuando se trata de competencias esenciales relacionadas con la supervisión y fiscalización de la prestación de servicios de interés público, como la salud, la atribución de responsabilidad puede surgir por la omisión en el cumplimiento del deber de supervisar la prestación del servicio para proteger el bien respectivo183".5

\footnotetext{
Corte Suprema de Justicia de la Nación, "Passero de Barriera, Graciela c/ Estado Nacional”, 18/09/2007, Fallos 330:4160.

5 Corte Interamericana de Derechos Humanos, "Poblete Vilches y otros vs. Chile", Sentencia de 8 marzo de 2018 (Fondo, Reparaciones y Costas). Parágrafo 124. Disponible en: http://www.corteidh.or.cr/docs/casos/articulos/seriec 349 esp.pdf.
} 


\section{Democracia}

Humanos e

Por último, cabe destacar que, como principio general, el paciente es un sujeto vulnerable. Ello es así, ya que cuando una persona hace un requerimiento a un profesional de la medicina, lo realiza por razones subjetivas o síntomas objetivos (dolores, angustia, etc.), en busca de un diagnóstico o tratamiento, que de por sí ante la afección lo vuelve una persona "vulnerable". Más aún, si frente a los requerimientos necesarios para el diagnóstico o tratamiento, se encuentra con vallas o impedimentos de la salud pública o de las empresas privadas que muchas veces lo obligan a ventilar temas que hacen a su dignidad frente a los tribunales. Sin dudas que esta persona automáticamente se transforma en paciente y pasa a integrar el denominado grupo de personas "vulnerables" y más aún si se encuentra inmersa en una relación o contrato de consumo, lo que lo convierte en un "consumidor hipervulnerable" - temática sobre la que retomaremos al final de este trabajo.

Es por ello que propugnamos por un lado que el "paciente" y el "consumidor" deben ser incluidos en el listado de las "100 Reglas de Brasilia"6, ya que su vulnerabilidad es palmaria - como ya lo ha consignado expresamente Brasil en los años 90 al regular el consumo en su país (artículo 4) - y merece la correspondiente protección del Estado en sus tres poderes.

Por otro lado, no hay duda en este contexto que tanto la salud pública como la semi pública (obras sociales) y la privada (empresas de medicina prepaga) son pasibles de la aplicación del daño punitivo, que en definitiva lo que persigue es procurar disuadir al dañador, evitando la imitación de conductas similares. Así se ha dicho que "La pena privada está estrechamente asociada a la idea de prevención de ciertos daños, y también a la punición y al pleno desmantelamiento de los efectos de ilícitos que, por su gravedad o por sus consecuencias, requieren algo más que la mera indemnización resarcitoria de los perjuicios causados"7. Dada la funcionalidad que tiene el daño punitivo - como se dijo punitiva y disuasoria de la realización de conductas perjudiciales para el consumidor-su importe es independiente de otras indemnizaciones que se fijen en cada caso particular

En definitiva, si el Estado no cumple y lo obliga al administrado tener que concurrir a la justicia para lograr las prestaciones de salud, no hay duda que se debe flexibilizar dicho acceso teniendo en cuenta la vulnerabilidad del paciente, siendo pasible en su caso, cuando su conducta sea reiterada e implique sobre todo un trato indigno y vejatorio para el paciente consumidor.

\section{PROTECCIÓN DE LA SALUD EN BRASIL}

La protección a la salud en Brasil, históricamente se presenta como una innovación de la constitución de 1988, cuando por primera vez la salud pasa a ser un derecho de todos. Así como en Argentina y en otros países, se advierte que la idea de universalidad de este derecho es muy reciente en la vida social. O mejor, la salud como un bien relacionado a la vida se ha convertido en un bien jurídico en los últimos 40 años. Hoy el concepto de salud tiene esta nueva e innovadora peculiaridad como afirma Aith (2007, p. 394): la salud como un bien jurí-

\footnotetext{
"Reglas de Brasilia sobre Acceso a la Justicia de las Personas en Condición de Vulnerabilidad", XIV Cumbre Judicial Iberoamericana, marzo de 2008. Texto completo disponible en: http://www.acnur.org/fileadmin/Documentos/BDL/2009/7037. pdf?file=fileadmin/Documentos/BDL/2009/7037.

Stiglitz Rubén y Pizarro Ramón D, “Reformas a la lay de defensa del consumidor" LL 2009-B,949.
} 


\section{Democracia}

Humanos e

dico relacionado de forma indisociable con el mayor bien jurídico que existe, la vida. La salud, lejos de ser sólo la ausencia de enfermedades o enfermedades, se configura en el estado de bienestar físico, social y mental.

El papel del Estado pasa a tener una función positiva en el sentido de asegurar también los derechos de igualdad. El proceso de ampliación de derechos es fruto de una demanda de la ciudadanía, que terminó por fomentar la intervención del Estado en el dominio económico y social, realidad que se evidencia a partir del siglo 20 (COSTA, 2001).

El texto constitucional receptó el concepto de salud como completo bienestar, sin embargo, no ha dejado de lado la concepción de la salud como mera ausencia de enfermedad. Ya que la salud y el equilibrio ambiental consagran el bienestar del ser humano, la salud debe ser analizada bajo dos prismas: el individual (subjetivo) y el colectivo, donde es notable su interfaz con la sociedad, donde los límites son impuestos al sujeto para que todos puedan gozar de tal derecho. La libertad individual debe estar en consonancia con la igualdad de dicho derecho social. Costa (2001, p. 154) dijo al respecto:

La Ley Mayor de la República estipuló para que la salud sea correctamente determinada en su texto. Así, vinculó su realización a las políticas sociales económicas y al acceso a las acciones y servicios destinados, no sólo, a su recuperación, sino también a su promoción y protección. En otras palabras, se adoptó el concepto que engloba tanto la ausencia de enfermedad, como el bienestar (...).

Es sabido que el problema que enfrenta el Estado contemporáneo es justamente el hecho de ser un Estado de modernidad tardía, que no logra concretar las promesas de la modernidad, entre las cuales se puede destacar la concreción de los derechos fundamentales. Así, nos interesa establecer una reflexión acerca del derecho a la salud, teniendo como paradigma el análisis del comunismo como posibilidad para la "reescritura de la judicialización y del derecho a la salud".

La actuación expansiva del Poder Judicial (MORAES, 2000) es un fenómeno que se ha tomado cuenta del final del siglo pasado. La gran mayoría de los países occidentales democráticos adoptó el Tribunal Constitucional como mecanismo de control de los demás poderes. Los Tribunales, en general, fueron insertados en el contexto político, y eso generó alteraciones en la gestión y en la implementación de las políticas públicas (MELLO, 1998). El gobierno, además de negociar su plan político con el Parlamento, tuvo que considerar la necesidad de no infringir la Constitución. En tesis, esa sería, de modo simplificado, la ecuación política que acopló el sistema político (democracia) y sus nuevos guardianes (la Constitución y los Jueces o Tribunal) (VIEIRA, 1994).

Este nuevo contexto de la arquitectura institucional propició el desarrollo de un ambiente político que posibilitó la participación del Poder Judicial en los procesos decisorios, incluyendo aquellos concernientes a las políticas públicas. Es que a pesar de la asimetría entre los poderes (LIJPHART, 1989), el Poder Judicial ha ocupado un espacio estratégico en el control de los demás, principalmente en el del Ejecutivo (WERNECK VIANNA, 1999). Si eso es positivo o negativo es otra discusión. En el escenario brasilero podemos observar las prerrogativas de control de constitucionalidad ejercida por el Supremo Tribunal Federal brasilero (STF) en el período posterior a la promulgación de la Carta Constitucional (BONAVIDES, 2012). 


\section{Democracia}

Humanos e

En lo que respecta al debate de la judicialización, en el contexto del Tribunal "controlador" podemos dividir la discusión en dos aspectos: el primero es el aspecto normativo, que trata de la, tal vez ilusoria, supremacía de la Constitución sobre las decisiones parlamentarias mayoritarias. Esa discusión es bastante pertinente teniendo en cuenta que aborda los dilemas de la evolución del constitucionalismo sobre el modelo tradicional (Westmister) de hacer o crear la política, o sea el debate entre democracia y constitucionalismo. En ese sentido es oportuno remarcar el debate normativo entre quienes están a favor de la judicialización, como Dworkin (2001) y Cappelletti (1993), los que están a favor siempre que se expresen ciertos límites, como Habermas (1997) y Garapon (1999) y los que están en contra, como Ely (1980).

El segundo aspecto es el analítico, que se preocupa por el ambiente político e institucional, con los "engranajes" del proceso político. Por lo tanto, este aspecto está preocupado en cómo definir, medir y evaluar el proceso de judicialización de la política. Este aspecto es extremadamente complejo. La verificación del fenómeno de la expansión del Poder Judicial en varias democracias posibilitó la creación de un marco de condiciones políticas que contribuyó para el entendimiento de ese proceso.

El estudio sobre el tema de la expansión del Poder Judicial fue objeto de discusión en la obra The Global Expansion of Judicial Power, organizado por Neal Tate y T. Vallinder (1995). El libro fue introducido en Brasil por Castro (1997), analiza casos de expansión y orientó el debate académico en la Ciencia Política en torno a la judicialización en Brasil. El proceso de expansión del Poder Judicial en Brasil se presenta en constante crecimiento, según investigaciones empíricas desarrolladas por estudiosos del área, hay un significativo aumento de las acciones judiciales (CASTRO, 1997).

El derecho al acceso a la salud ya es un tema recurrente en el Poder Judicial, hay un aumento permanente de la demanda que revela un dilema para el Poder Judicial: cómo tomar decisiones que, de hecho, beneficiarán a los pacientes, sin desequilibrar el sistema de salud. Actualmente, hay más de dos millones de acciones en salud, según datos recientes del Informe Justicia en Cifras, del CNJ (Consejo Nacional de Justicia). La mayoría de los casos involucran solicitudes de acceso a procedimientos y medicamentos, muchos de ellos incluidos en la lista del Sistema Único de Salud (SUS), pero desatendidos por el Estado. Y otros que no siempre están cubiertos por el gobierno o incluso por los planes de salud: estos son, por ejemplo, medicamentos en fase experimental (CNJ, 2020)

Apoyada en el acceso al derecho a la salud garantizado en la Constitución Federal, la judicialización interfiere en la administración de los recursos de salud, incidiendo en la planificación de las tres esferas de gobierno: municipal, estatal y federal. Entre 2008 y 2017 hubo un aumento del $130 \%$ en las acciones de salud, según una encuesta del Departamento de Investigaciones Judiciales (DPJ/CNJ) "Judicialización de la salud en Brasil: perfil de demandas, causas y propuestas de soluciones". Los datos muestran que el sector salud fue responsable de 498.715 casos en primera instancia, distribuidos en 17 tribunales de justicia estatales; y 277.411 casos en segunda instancia, distribuidos en 15 juzgados estatales. El impacto en el presupuesto del Ministerio de Salud fue un aumento de 13 veces en el gasto en reclamos judiciales: en 2016 alcanzó R\$ 1,6 mil millones (CNJ, 2020). 


\section{Democracia}

Humanos e

Los datos son de 2019 (informe más "actualizado" del CNJ), y es oportuno destacar que algunos Tribunales Estatales de Justicia no informaron el número de acciones al CNJ, o sea, los datos son aún más alarmantes, en función de los datos poco precisos y la falta de periodicidad de la información.

En el contexto de la expansión del Poder Judicial, del macizo número de demandas judiciales con el objeto derecho a la salud involucradas en la judicialización de la política y de la crisis del Estado, ese ítem pretende analizar, en Brasil, la expansión judicial en el sesgo de la judicialización de la salud y la necesaria (re)lectura de ese fenómeno.

En el proceso de expansión judicial, no podemos olvidar el cambio de comportamiento jurisprudencial de los tribunales: el Judicial pasa a actuar en los "pseudos vacíos" dejados por los poderes Ejecutivo y Legislativo (poderes representativos directos) (IBAÑEZ, 2003). Este cambio paradigmático en la actuación de los tribunales está vinculado, también, a los cambios interpretativos de las escuelas jurídicas y a la crisis del Positivismo Jurídico (FARIA, 2002).

¿La expansión del Poder Judicial en el contexto de la judicialización es una consecuencia de la crisis del Estado o es un presupuesto? No se tiene respuesta acabada para este cuestionamiento; sin embargo, hay algunas posibilidades señaladas por Arguelhes e Leal. El autor hace un resumen de los factores más comunes enunciados por la doctrina de lo que serían las causas para la judicialización en Brasil, a saber: 1) la canalización en el Poder Judicial de expectativas sociales frustradas ante un Legislativo y un Ejecutivo defectuosos, parcialmente inoperantes; 2 ) el rediseño del sistema brasileño de control de constitucionalidad en la Constitución de 1988, ampliando no sólo el poder de control del Supremo Tribunal Federal, sino también los canales por los cuales diferentes actores políticos y sociales podrían provocar la actuación del Tribunal; 3) la "constitucionalización integral", con la adopción de un texto constitucional bastante amplio y detallado, abriendo espacio, así, para la discusión de cuestiones que antes eran consideradas políticas y ahora son consideradas jurídicas, o sea, judicializables; 4) el comportamiento estratégico por parte de actores políticos que ven en la intervención judicial la oportunidad de revertir decisiones desfavorables en espacios decisorios mayoritarios, como el Congreso Nacional y 5) la creciente consolidación de la democracia en el país, al movilizar la ciudadanía en la búsqueda de instrumentos para concretar derechos fundamentales y fortalecer al Poder Judicial como actor relativamente independiente de la actuación de las fuerzas políticas del momento (ARGUELHES; LEAL, 2009).

No es posible ignorar el impacto de la llegada brutal de la miseria, de la ausencia de medios, del descubrimiento de todas las perversiones de una sociedad permisiva en la jurisdicción (ROUGER, 2007). Es ante esta realidad que debemos pensar en el derecho que de complicado pasó a complejo; que de derecho reloj pasó a un derecho nube, o sea, un derecho que evolucionó (ADAM, 2007). En esta evolución, no cabe duda de que el derecho a la salud es un derecho subjetivo de todo ciudadano, que genera como efecto el deber del Estado de propiciarlo, so pena de ser incitado judicialmente para ello, pues se garantiza recurrir al Poder Judicial en lo que se refiere a la búsqueda de la tutela jurisdiccional, a fin de verificar el cumplimiento de la obligación debida por el Estado. Siendo ese un derecho subjetivo, el individuo y el Estado son conducidos a una relación jurídica del tipo obligacional (SCHWARTZ; GLOECKNER, 2003), o sean hay una expectativa jurídica en relación a la salud. 


\section{Democracia}

Humanos e

Cuando se habla de judicialización de la política, se lo hace también de la politización del derecho; hay un exceso, una especie de hipertrofia en detrimento del Estado de Derecho y de la propia democracia. Las intervenciones judiciales (politización del derecho) interfieren en la autonomía y el funcionamiento del sistema político (en particular en la administración). En ese contexto, lo que se vive en la práctica es una "ponderación ad hoc" sin perspectiva a largo plazo (NEVES, 2014). La judicialización de la salud es precisamente eso: ponderación ad hoc de las políticas públicas de salud.

A partir del reconocimiento de la salud como derecho, la búsqueda por la tutela jurisdiccional con la expectativa de dar efectividad al derecho a la salud (expectativa normativa), muchas veces, en una situación de crisis y escasez de recursos, en ambiente de fuerte tensión, se acaba obteniendo lo que se ha convenido como judicialización de la política, teniendo en cuenta que las promesas (expectativas) constitucionales se ven frustradas. Esta frustración genera la búsqueda de la tutela jurisdiccional para viabilizar la efectivación, la realización de dicho derecho (MORAIS, 2008).

Adviértase que, pese a la judicialización haya desarrollado un importante papel en sus principios, hay un gran dilema del sujeto egoísta: todavía existe la dicotomía del individual $\mathrm{x}$ colectivo. Hay una interferencia en la política pública, concebida en el corazón del Poder Ejecutivo.

Ante la interferencia desenfrenada del Poder Judicial en las políticas públicas, son oportunas las observaciones de Campilongo acerca del riesgo de una "Constitución en la versión colcha de retazos" (CAMPILONGO, 2000). El autor nos advierte que son grandes los riesgos de una posible fragmentación del propio derecho constitucional, es decir, una constitución en la versión colcha de retazos, manipulada y utilizada en un estilo pret-à-porter. Es innegable que son grandes los riesgos de condicionar la interpretación de la Constitución a un determinado modelo político coyuntural. Estamos ante el riesgo de una politización del propio orden constitucional.

La búsqueda del Poder Judicial, en el acceso al bien constitucional salud puede ser vislumbrada, inicialmente, como eminentemente individual, pues se verifica que las demandas, en su mayoría, se refieren a la prestación de remedios o tratamientos específicos. En ese orden existe otro gran problema: el acceso a la justicia, el cual precede al propio acceso al derecho (MORAIS, 2008). En lo que se refiere al derecho a la salud, se percibe que, en la mayoría de los casos, quien realmente buscará judicialmente la efectividad de su derecho es quien tiene condiciones para costear a un abogado o quién es culturalmente un poco más informado para buscar la Defensoría Pública.

Observamos que dentro de la judicialización de la salud, tenemos una dicotomía: el acceso al derecho a la salud y el no acceso. La crisis que asola el Estado alcanza directamente este fenómeno y se traduce en: cuánto más crisis, más judicialización. En otras palabras, ingresan al Poder Judicial requiriendo medicamentos o cualquier otra prestación sanitaria, sólo los individuos que tienen acceso a un abogado o a la Defensoría Pública. Se crea un verdadero círculo vicioso. Es la búsqueda desenfrenada, en el contexto de crisis del Estado, por el máximo de salud que se pueda alcanzar en el ámbito judicial, buscando sólo la satisfacción individual, estilo free rider. 


\section{Democracia}

Humanos e

La figura del free rider es oportuna para ilustrar una de las facetas de la judicialización: el individuo que utiliza el aparato judicial, que acaba por interferir directamente en el Ejecutivo y en la política pública de salud, es el reflejo del sujeto moderno, egoísta, casi un sujeto hobbesiano. ${ }^{8}$ Es el individuo calculador que deja deliberadamente a los demás la carga y el onus de su satisfacción personal. Se aprovecha de la no exclusividad del bien salud y se utiliza de la lógica de "pseudo prorrateo o división" con la colectividad, o sea, los perjuicios y costos generados por la judicialización serán soportados por todos. Este sujeto egoísta ignora el paradigma de lo común, de hacer de la salud algo común; no actúa colectivamente (LAVAL; DARDOT, 2014).

\section{REFLEXIONES FINALES}

Hoy en día, la Justicia sigue haciendo hincapié en muchas de sus decisiones en el ámbito interno y deja de lado normas que, si bien son supraestatales, forman parte también del esquema legal que es posible utilizar para solucionar los conflictos.

Un ejemplo de esto es que el Código Civil y Comercial de la República Argentina ha sentado las bases para la interpretación de las causas que se someten a su competencia. En ella, ha recordado la importancia para los operadores jurídicos de tener presente su aplicabilidad de conformidad con la Constitución y los Tratados Internacionales de Derechos Humanos en los que la República es parte. ${ }^{9}$ Existen, entonces, una multiplicidad de mandatos que llevan a que el sistema regional se tenga presente.

La justicia, si bien quiere ser cercana, queda en muchas oportunidades alejada de la realidad y de las circunstancias más conflictivas para los ciudadanos, como es la salud. Por esto es que creemos que en éste ámbito debe primar en el acceso a la justicia una mirada más humana de los tribunales y por ello debemos comprender la interrelación e importancia que tiene este acceso a la luz del Sistema Interamericano.

Hoy "el interés del Derecho por asegurar el acceso a la justicia se explica por los niveles de pobreza que azotan los distintos países latinoamericanos, incluida la Argentina" (SARTORI, 2010 , p. 257) y Brasil. Los altos grados de desigualdad que vivimos hacen que "la población padezca una sensación de inaccesibilidad, como así también un progresivo desmoronamiento de la confianza en el sistema que lleva a quien haya transitado este camino a no querer hacerlo nuevamente" (OTAMENDI, 2006, p. 241).

\footnotetext{
El sujeto hobbesiano puede ser ilustrado de diferentes modos. La guerra de todos contra todos no se deriva, en modo alguno, de la escasez. Hobbes destaca que, a diferencia de los animales que, cuando están satisfechos, tienden a una convivencia pacífica con sus semejantes e incluso con animales de especies enemigas, los hombres, cuanto más satisfechos estén, más tenderán a implicar con los demás. Según Agostinho Ramalho Marques Neto, en Hobbes y las pasiones, El sujeto hobbesiano es un sujeto monádico, un in-di-ví-dúo, uno que no hace dos, tanto en el estado de naturaleza, como en la vida en sociedad. Incluso habiendo pasado, en esta última situación, a la condición de socius, él sigue siendo tan monádico como antes. Hay una suposición de unidad del sujeto tan firmemente establecida, que casi nunca se menciona, quedando subentendida.

9 Cfr. Art. 1: [Fuentes y aplicación. Los casos que este Código rige deben ser resueltos según las leyes que resulten aplicables, conforme con la Constitución Nacional y los tratados de derechos humanos en los que la República sea parte. A tal efecto, se tendrá en cuenta la finalidad de la norma. Los usos, prácticas y costumbres son vinculantes cuando las leyes o los interesados se refieren a ellos o en situaciones no regladas legalmente, siempre que no sean contrarios a derecho], Código Civil y Comercial de la Nación Argentina.
} 


\section{Democracia}

Humanos e

La luz que nos brindan hoy los índices de marginalidad, de desalfabetización, de crecimiento del desempleo, entre otros, nos dan la pauta para comprender por qué el acceso a la justicia debe ser asegurado al justiciable, porque no puede haber voz que clame justicia y que no sea oída. Por este motivo es que se necesitan espacios de discusión, de investigación y de proyección de ideas que permitan que todos y todas puedan gozar de este derecho y accedan a los tribunales en la búsqueda de obtener una respuesta rápida y eficiente.

Las estadísticas sobre la judicialización de la salud en Brasil son alarmantes. Si contemplamos todas las exigencias en materia de salud. En tiempos de la pandemia de Covid-19, es posible esperar que este escenario empeore aún más. Debido a la actual situación de la pandemia de Covid-19, el Estado ha descuidado la atención de otras enfermedades no menos importantes, como el cáncer, problemas cardíacos, en definitiva, enfermedades crónicas no transmisibles. Por ello, a pesar de la ausencia de datos estadísticos oficiales en 2020, se estima que la crisis pandémica está contribuyendo a un aumento aún mayor en el número de demandas interpuestas por particulares contra el Estado, relacionadas con el derecho a la salud.

\section{REFERENCIAS}

ABRAHIMOVICH, Víctor. Acceso a la justicia y nuevas formas de participación en la esfera política. Buenos Aires: Abeledo Perrot, 2006.

ADAM, M. Retornos de experiência de ação em sistemas complexos. In: MORIN, E.; MOIGNE, J-L. (org.). Inteligência da complexidade - epistemologia e pragmática. Lisboa: Instituto Piaget, 2007.

AITH, Fernando Mussa Abujamra. Curso de Direito Sanitário: a proteção do direito à saúde no Brasil. São Paulo: Quartier Latin do Brasil, 2007.

ALTERIO, Ana Micaela. Los (des) incentivos económicos para facilitar el acceso a la justicia. Una crítica desde el análisis económico del derecho. Buenos Aires: La Ley On-line AR/DOC/3063/2008, 2008.

ARENDT, H. A condição humana. Tradução Roberto Raposo. Posfácio Celso Lafer. 10. ed. Rio de Janeiro: Forense Universitária, 2001.

ARGUELHES, D. W.; LEAL, F. R. Pragmatismo como [meta]teoria da decisão judicial: caracterização, estratégias e implicações. In: SARMENTO, D. Filosofia e teoria constitucional contemporâneas. Rio de Janeiro: Lumen Juris, 2009.

BÁEZ, Julio C. Gestión judicial y acceso a la justicia. Buenos Aires: La Ley On-line AR/DOC/1717/2013, 2013.

BASTERRA, Marcela. La Corte y los derechos. Un informe sobre el contexto y el impacto de sus decisiones durante el período2003/2004. Buenos Aires: Abeledo Perrot № 0003/012556, 2006.

BERIZONCE, Roberto. Efectivo Acceso a la Justicia, Buenos Aires: Libreria Editora Platense S.R.L., 1987.

BESSONE, Nancy M.; SCHERBATH, Federico; TONTO, Mariana L. La acordada de la CSJN N 4/2007 a la luz de los principios de igualdad, acceso a la justicia, debido proceso y razonabilidad. Buenos Aires: La Ley On-line AR/ DOC/2408/2011, 2011.

BIDART CAMPOS, Germán. Manual de la Constitución Reformada. Buenos Aires: Ediar, [1996?].

BIRGIN, Haydee; KOHEN, Beatriz (comp.). Acceso a la Justicia como garantía de igualdad: instituciones, actores y experiencias comparadas. Buenos Aires: Biblos, 2006.

BONAVIDES, P. Curso de Direito Constitucional. São Paulo: Malheiros, 2012.

BRASIL. Conselho Nacional de Justiça. Dados extraídos do sistema de acompanhamento da Resolução CNJ n. 107, em junho de 2014. Disponível em: http://www.cnj.jus.br/images/programas/forumdasaude/demandasnostribunais.forumSaude.pdf . Acesso em: 16 mar. 2019.

BUSCAGLIA, Edgardo. Derechos humanos, acceso a la justicia y análisis económico del derecho. Buenos Aires: Abeledo Perrot № AP/DOC/1611/2014, 2014.

BUSTAMANTE CANO, María Noelí. Acceso a la justicia. El Pacto de San José de Costa Rica y los Derechos Humanos (Evolución de los criterios de la Corte Suprema de Justicia de la Nación). Buenos Aires: La Ley Online AR/ DOC/497/2001, 2001.

CALABRIA, Daniel Nicolás; PERRONE, Nicolás Marcelo. “Estado, Acceso a la Justicia y Sociedad. Una Visión Totalizadora". Acceso a la Justicia. Buenos Aires: La Ley, 2006. 


\section{Democracia}

Humanos e

CAMPILONGO, C. F. O direito na sociedade complexa. São Paulo: Max Limonad, 2000.

CAMPILONGO, C. F. O Judiciário e a democracia no Brasil. Revista USP, São Paulo, n. 21, 1994, p. 116-125.

CANOTILHO, J. J. G. O estado adjetivado e a teoria da constituição. Interesse Público, n. 17, p. 13 et seq., jun. 2011. Disponível em: http://amdjus.com.br/doutrina/constitucional/34.htm. Acesso em: 15 jan. 2019.

$\mathrm{CAO}$, Christian Alberto. Control de constitucionalidad más control de convencionalidad. Un nuevo paso en la tutela de los derechos fundamentales. Buenos Aires: La Ley On-line AR/DOC/6812/2010, 2010.

CAPPELLETTI, Mauro; GARTH, Bryant. El acceso a la justicia: la tendencia en el movimiento mundial para hacer efectivos los derechos. México: Fondo de Cultura Económica, 1996.

CAPPELLETTI, M. Juízes legisladores? Porto Alegre: Sérgio Antonio Fabris, 1993.

CASTRO, M. F. O Supremo Tribunal Federal e a judicialização da política. Revista Brasileira de Ciências Sociais, São Paulo, v. 12, n. 34, jul. 1997.

CNJ. Conselho Nacional de Justiça. Justiça em Números 2020: ano-base 2019. Brasília: CNJ, 2020.

CNJ. Conselho Nacional de Justiça. Judicialização da saúde no Brasil: perfil das demandas, causas e propostas de solução. Brasília: CNJ, 2019.

CONVERSET, Martin M. La posibilidad del acceso a la justicia: ¿es una tarea que nos corresponde a todos? Buenos Aires: La Ley On-line AR/DOC/305/2005, 2005.

COSTA, E. V. O Supremo Tribunal Federal e a construção da cidadania. São Paulo: Institutos de Estudos Jurídicos e Econômicos, 2001.

COSTA, Luiz Fernando Gaspar. Listagem de medicamentos e a decisão proferida na STA n. 59-STJ. A justiciabilidade dos direitos sociais. Revista Direito Sanitário. São Paulo, v. 5, n. 1. 2004.

DALLA VÍA, Alberto. Sobre el derecho y la justicia en el Mercosur. Buenos Aires: El Derecho Tomo 148, 1992.

DEL CARRIL, Santiago. Las redes sociales para el acceso a la justicia. Buenos Aires: La Ley Online AR/ DOC/6045/2010, 2010.

DWORKIN, R. A justiça de toga. São Paulo: Martins Fontes, 2010.

DWORKIN, R. Uma questão de princípios. São Paulo: Martins Fontes, 2001.

ELY, J. H. Democracy and Distrust: a Theory of Judicial Review. Cambridge, Mass: Harvard University, 1980.

FARIA, J. E. O Direito na economia globalizada. São Paulo: Malheiros, 2002.

FUENTES ALCEDO, Carlos Iván. "Protegiendo el Derecho a la Salud en el Sistema Interamericano de Derechos Humanos: Estudio Comparativo sobre su Justiciabilidad desde un Punto de Vista Substantivo y Procesal". American University International Law Review, v. 22, Issue I, 2006.

GARAPON, A. O juiz e a democracia: o guardião de promessas. Rio de Janeiro: Revan, 1999.

GHERSI, Enrique Silva. Una introducción al análisis económico del derecho. Advocatus, n. 7, p. 147-153, 2002. https://doi.org/10.26439/advocatus2002.n007.2384

HABERMAS, J. Direito e democracia - entre facticidade e validade. Rio de Janeiro: Tempo Brasileiro, 1997.

IBAÑEZ, P. A. Democracia com juízes. Revista do Ministério Público, Lisboa, a. 24, n. 94, p. 31-47, jun. 2003.

LAVAL, C.; DARDOT, P. Común: ensayo sobre la revolución en el siglo XXI. Barcelona: Gedisa Editorial, 2014.

LÉVINAS, E. Entre nós. Ensaios sobre a alteridade. 2. ed. Tradução Pergentino S. Pivatto (coord.) et al. Petrópolis, RJ: Vozes, 2005.

LEZCANO, Juan Manuel. El elemento cultural en la Teoría General del Acceso a la Justicia. Buenos Aires: La Ley Online AR/DOC/344/2012, 2012.

LORENZETTI, Ricardo. A empresa médica. Buenos Aires: Editorial Rubinzal-Culzoni Editores, 1998.

LIJPHART, A. As democracias contemporâneas. Lisboa: Gradiva, 1989.

MARQUES, S. B.; DELDUQUE, M. C. O direito social à saúde deve ser garantido por políticas públicas e decisões judiciais. In: DELDUQUE, M. C. (org.). Temas atuais de direito sanitário. Brasília: CEAD; FUB, 2009.

MARQUES NETO, Agostinho Ramalho. A ciência do direito: conceito, objeto, método. Imprenta: Rio de Janeiro, Renovar, 2009.

MASSAU, G. C. As primeiras linhas de uma possível reescrita do Estado. Revista Meta Juris, n. 1, mar. 2012, p. 175-205.

MELO, M. C. Constitucionalismo e ação racional. Lua Nova [on-line]. 1998, n. 44, p. 55-79, 1998. DOI: http://dx. doi.org/10.1590/S0102-64451998000200004. Acesso em: 24 jan. 2019.

MORAES, A. Jurisdição constitucional e tribunais constitucionais. São Paulo: Atlas, 2000.

MORAIS, J. L. B. de. O Estado Social e seus limites. Condições e possibilidades para a realização de um projeto constitucional includente. In: Caderno de Direito Constitucional. Porto Alegre: TRF - 4a Região, 2008. (Módulo 5). 


\section{Democracia}

Humanos e

NEVES, M. Entre Hidra e Hércules. Princípios e regras constitucionais. São Paulo: Martins Fontes, 2014.

O'DONNELL, G. "On the state, democratization and some conceptual problems: A Latin American view with glances at some postcommunist countries". World Development, n. 21, v. 8, p. 1.355-1.369, august 1993.

ORTEGA, F. Para uma política da amizade: Arendt, Derrida, Foucault. Rio de Janeiro: Relume Dumará, 2000.

OTAMENDI, Santiago. "El acceso a la Justicia: ¿Una renovada utopía del Siglo 21? Una mirada sobre las barreras que impiden a los sectores más carenciados de la sociedad el pleno acceso al sistema de justicia". Acceso a la Justicia. Buenos Aires: La Ley, 2006.

PÉREZ CURCI, Juan Ignacio. Derecho de acceso a la justicia en el sistema interamericano de derechos humanos. Buenos Aires: La Ley On-line AR/DOC/1755/2014, 2014.

PETRACCHI, Enrique S. Acceso a la Justicia. Buenos Aires: La Ley On-line AR/DOC/1251/2004, 2004.

PINTO, Monica. El principio pro homine. Criterios de hermenéutica y pautas para la regulación de los derechos humanos. In: ABREGÚ, Martín; COURTIS, Christian. La aplicación de los tratados de derechos humanos por los tribunales locales. Centro de Estudios Legales y Sociales (CELS). Buenos Aires, Argentina: Editores del Puerto, 2004.

ROUGER, M. Entre dever de prospectiva e obrigação de retrospectiva. In: MORIN, E.; MOIGNE, J-L. (org.). Inteligência da complexidade - epistemologia e pragmática. Lisboa: Instituto Piaget, 2007.

SANTOS, B. Direito e democracia: a reforma global da justiça. Porto: Afrontamento, 2001.

SARTORI, José Antonio. "Acceso a la justicia y Beneficio de Litigar sin Gastos: Estudio de la efectividad del procedimiento establecido para el acceso a la justicia en el Fuero Civil de la Primera Circunscripción sede Córdoba capital". La interdisciplinariedad desde la Investigación en el Poder Judicial de la Provincia de Córdoba. Córdoba: Centro de Perfeccionamiento Ricardo C. Núñez, 2010.

SCHWARTZ, G.; GLOECKNER, R. J. A tutela antecipada no direito à saúde. A aplicabilidade da Teoria Sistêmica. Porto Alegre: Safe, 2003.

STRECK, L. L. Jurisdição constitucional e hermenêutica. Uma nova crítica ao Direito. Porto Alegre: Livraria do Advogado, 2002.

TABOSSI, Ramiro J. El acceso a la justicia mediante las acciones colectivas. Buenos Aires: La Ley On-line AR/ DOC/6672/2011, 2011.

TATE, C. N. Why the Expansion of Judicial Power? In The Global Expansion of Judicial Power. New York: New York University, 1995.

TATE, C. N.; VALLINDER, T. The global expansion of judicial power. New York: New York University Press, 1995.

VIEIRA, O. V. O Supremo Tribunal Federal e a consolidação da democracia: 1988 a 1993. 1994. Dissertação (Mestrado em Ciência Política) - Universidade de São Paulo, São Paulo, 1994.

WERNECK VIANNA, L. A judicialização da política e das relações sociais no Brasil. Rio de Janeiro: Revan, 1999. 